\title{
Integrating biophysical and whole-farm economic modelling of agricultural climate change mitigation
}

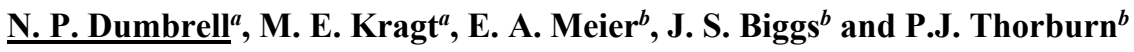 \\ ${ }^{a}$ School of Agricultural and Resource Economics, University of Western Australia, M089/35 Stirling \\ Highway, Crawley, WA, 6009 \\ ${ }^{b}$ CSIRO Agriculture Flagship, Queensland Bioscience Precinct, 306 Carmody Road, St Lucia, QLD, 4067 \\ Email:nikki.dumbrell@uwa.edu.au
}

\begin{abstract}
Agriculture is the source of 16 percent of Australia's greenhouse gas (GHG) emissions. Research has shown that changes in agricultural practices can increase carbon sequestration in soils and/or vegetation and reduce GHG emissions. Given worldwide commitments to reduce GHG emissions, there is a need to better understand the potential for Australian agriculture to contribute to GHG mitigation. GHG abatement practices will only be adopted if profitable to farmers. Without strong evidence for increased profitability, there is no incentive for farmers to move away from their current practices. Therefore, it is necessary to incorporate economics in any assessment of the potential for Australian farms to contribute to GHG mitigation.
\end{abstract}

We performed an integrated modelling exercise to predict the GHG mitigation potential and whole-farm economic implications of different mitigation practices that can be implemented on Australian grain farms. This exercise was undertaken in two stages. In the first stage, a range of potential management practices that could provide GHG abatement were identified; these involved adding extra organic matter to the soil or altering nitrogen fertiliser use. The Agricultural Production Systems sIMulator (APSIM) was used to estimate the effects of abatement practices on productivity, soil carbon sequestration, nitrous oxide emissions and net GHG emissions over time. In the second stage, we develop an economic model that predicts annual revenues at a paddock scale, as well as whole-farm costs and benefits. Taking a whole-farm approach ensures that the full costs of different practices, such as investment in new capital equipment, is included.

We present results for a 6,000 hectare dryland cropping farm in the north-central wheatbelt of Western Australia. This area is representative of the typical Mediterranean climate found in some of Australia's major grain growing regions. We predict that stubble retention and other organic matter additions increase soil carbon, which is important for greenhouse gas emissions reductions. Productivity gains are possible under some of the GHG abatement practices, i.e. GHG abatement and productivity gains can be achieved simultaneously. Increasing nitrogen fertiliser application or replacing volunteer, weedy pastures with improved, legume pastures are predicted to increase earnings and operating profits. However, when accounting for interest and tax, there was no economic advantage or disadvantage of adopting any of the GHG abatement practices. While gross margins per hectare are positive in almost every season, the whole-farm annual profits were negative for 30-40 percent of years.

This study demonstrates the benefits of comprehensive economic analyses to accompany any biophysical analyses of the GHG mitigation potential of the Australian agricultural industry, and outlines a framework in which economic and biophysical analyses can be combined.

Keywords: Greenhouse gas, nitrous oxide, carbon sequestration, grain production, gross margins 


\section{INTRODUCTION}

The Australian agricultural sector is the source of 16 percent of national greenhouse gas emissions (DCCEE, 2010). The most important greenhouse gases (GHGs) emitted by dryland cropping systems are carbon dioxide $\left(\mathrm{CO}_{2}\right)$ and nitrous oxide $\left(\mathrm{N}_{2} \mathrm{O}\right)$. Dryland cropping is a source of GHGs emitted from soil cultivation, burning crop residues, soil erosion, the decomposition of organic carbon pools and the use of nitrogen fertilisers (Dalal et al., 2003; Luo et al., 2010; Rochecouste et al, 2015). Management practices (such as tillage, fertiliser use, cropping intensity, residue burning) can be altered to limit the emissions of GHGs from dryland cropping systems.

The Australian government has created opportunities for Australian farmers to contribute to national GHG emissions reduction targets and hence contribute to climate change mitigation. The current policy initiative to reduce GHG emissions from agriculture is the Emissions Reduction Fund (ERF, Parliament of the Commonwealth of Australia, 2014). Under the ERF, farmers can be compensated for costs associated with adopting management practices or projects that reduce emissions of greenhouse gases or increase carbon stocks in soil or vegetation. If farmers wish to engage in this policy and be compensated for their costs, they must place a bid in a reverse auction that outlines a price per unit of emissions abatement. The government will buy the least cost abatement achieved using certain methods. We need to understand the costs of GHG abatement such that we can know whether farmers are able to compete in these auctions.

Farmers are most likely to adopt conservation practices when they perceive that the change will enhance the realisation of their personal goals (Pannell et al. 2006). These goals are commonly a mix of economic, environmental and social objectives. Therefore, demonstrated productivity and economic advantage from GHG abatement practices is important to stimulate their widespread adoption.

To identify practices that support both GHG abatement and profitability the trade-offs between net GHG abatement and farm profitability need to be identified. In this paper, we present a modelling approach that incorporates the biophysical modelling of crop growth and greenhouse gas emissions as well as economic modelling of per hectare revenues (gross margins) and whole-farm profits. We use this modelling framework to look at: (1) the trade-offs that may exist between farm productivity, profitability and greenhouse gas abatement; (2) the economic feasibility of a range of GHG mitigation practices; and (3) the practices that can reduce emissions at no cost to farmers' profitability.

\section{METHODS}

We use case study farms to assess the biophysical capacity and economic feasibility of Australian grain farmers to contribute to GHG abatement. In this paper, we present results for our case study farm in the West Australian wheatbelt. A baseline for farming practices was established in consultation with local farmers and farmer groups. We then characterised a range of practices that have the potential to contribute to GHG abatement (Section 2.2). These GHG abatement practices were modelled alongside the baseline practices to analyse any resultant differences in GHG emissions, crop productivity and farm profitability. We simulated the use of the GHG abatement practices for 100 years to match the international permanence standard for carbon sequestration. We also considered the 25 year permanence options recently introduced in the Australian policy framework (Parliament of the Commonwealth of Australia, 2014).

\subsection{Case study farm}

In this paper, we present results for a case study farm located near Dalwallinu in the northern wheatbelt of Western Australia. This area has a typical Mediterranean climate with an average (winter-dominant) rainfall of $310 \mathrm{~mm} \mathrm{yr}^{-1}$. Seven soil types ranging from sands to clays were identified for the area. Each of the soil types were included (in varying proportions) for the 6,000 hectare case study farm (Figure 1). This is a croppingonly farm system that includes three rotations, with each rotation grown on each of the seven soil types (Figure 1). We simulate crop sowing between 25 April and 15 June. No crops were grown during the summer months and weeds were controlled by spraying. Under the base-case scenario, non-legume crops were supplied with a target amount of nitrogen fertilizer of $40 \mathrm{~kg} \mathrm{~N} \mathrm{ha}^{-1}$ per tonne of expected grain yield. Minimum tillage was practiced at the farm but crop residues were burned in March each year to destroy weed seeds prior to sowing the next crop. 'Pasture' in rotation 3 was unimproved and was not grazed. 


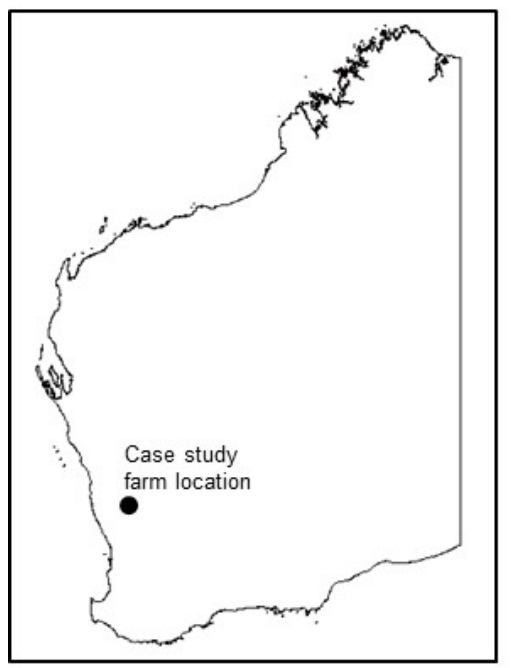

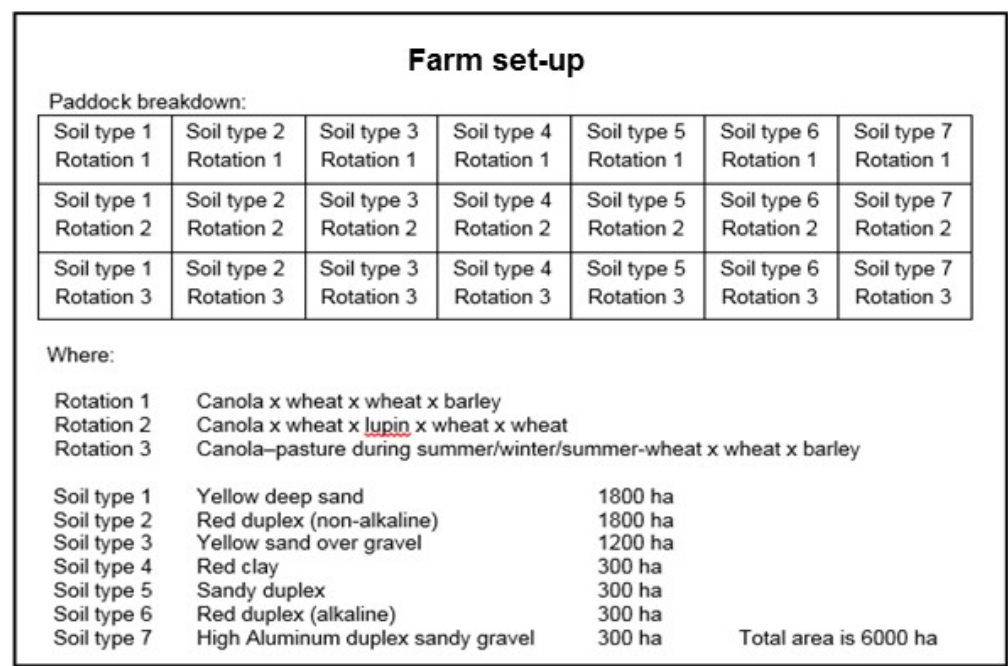

Figure 1. Case study farm location and set-up with rotation-soil type combinations used in simulations. Map from, University of Melbourne 2001.

\subsection{Greenhouse gas abatement practices}

Ten practices (scenarios) were simulated in our model to determine GHG abatement (Table 1). These practices are expected to mitigate greenhouse gas emissions by increasing carbon sequestration and/or reducing $\mathrm{N}_{2} \mathrm{O}$ emissions compared to baseline practices (Scenario 1). Abatement practices include retaining instead of burning stubble (Scenarios 2, and 5-10); modifying nitrogen fertiliser rates (Scenarios 3-6); and adding organic matter as manure (Scenario 7), summer crops (Scenarios 8 and 10) or improved pasture (Scenarios 9 and 10).

Table 1. Baseline practices (Scenario 1) and alternative practices (Scenarios 2-10) at the case study farm

\begin{tabular}{ll}
\hline No. & Description \\
\hline Scenario 1 & Stubble burnt, bare summer fallow, weedy pasture in the pasture phase (baseline) \\
Scenario 2 & Stubble retained \\
Scenario 3 & Stubble burnt, 125\% of baseline N fertiliser rate \\
Scenario 4 & Stubble burnt, 75\% of baseline N fertiliser rate \\
Scenario 5 & Stubble retained, 125\% of baseline N fertiliser rate \\
Scenario 6 & Stubble retained, 75\% of baseline N fertiliser rate \\
Scenario 7 & Stubble retained, 5 Mg ha $\mathrm{M}^{-1}$ manure applied every 5 years \\
Scenario 8 & Stubble retained, summer fallow green manure crop \\
Scenario 9 & Stubble retained, improved legume pasture in place of weedy pasture \\
Scenario 10 & Combine scenarios 8 and 9 \\
\hline
\end{tabular}

\subsection{Biophysical modelling}

The APSIM model (Holzworth et al., 2014) was used to predict crop yield, $\mathrm{N}_{2} \mathrm{O}$ emissions and changes in soil organic carbon for each scenario (Table 1) on each soil type. APSIM was configured with modules for soil nitrogen (APSIM-SoilN; Probert et al. 1998; Thorburn et al. 2010), soil water dynamics (APSIM-SoilWat; Probert et al. 1998), soil temperature (APSIM-SoilTemp2, following Campbell, 1985), residue (APSIMSurfaceOM; Probert et al., 1998; Thorburn et al., 2001), and growth of the different crops in the scenarios. Soil types that matched those selected for the case study farm were obtained from the APSoil database provided in APSIM, and modified with properties measured in the farm area where available. All soil-scenario combinations were simulated with the Wubin climate record obtained from the SILO database (Jeffrey et al., 2001).

Each soil-rotation-scenario combination was modelled over a 100 year period. Simulations were run for 10 different starting years in case cyclical patterns in climate unduly affected crop yields and soil carbon. The 10 starting years commenced in the successive years from 1906 to 1915 (i.e. the periods 1906-2005 to 1915-2014). The results were averaged over the simulations with different starting years. 
We determine net global warming potential (GWP) for each scenario, expressed in $\mathrm{CO}_{2}$-equivalents. We account for $\mathrm{N}_{2} \mathrm{O}$ emissions and changes in soil organic carbon (SOC). These were converted to carbon dioxide equivalents $\left(\mathrm{CO}_{2} \mathrm{e}\right)$ using the Intergovernmental Panel for Climate Change methodology (IPCC, 2013) ${ }^{1}$.

\subsection{Economic modelling}

The first part of the economic modelling was a paddock scale gross margin calculation. Such gross margin analysis is common in agricultural research (e.g. Huth et al., 2010; Kragt and Robertson, 2014) and was used to assess the impacts of management changes on revenue. The crop yield predicted by APSIM was multiplied by the crop price to give revenue from cropping on a per hectare basis. Gross margins were calculated as revenue minus variable costs (equation 1).

$$
\text { Gross margin }\left(\$ / \text { ha } \mathrm{r}^{-1}\right)=(\text { crop yield } \times \text { crop price }) \text { - variable costs }
$$

The variable costs include all costs relating directly to cropping: seed and seed treatment costs; seeding fuel costs; chemical and spraying costs; crop insurance costs; fertiliser costs (including freight and spreading); lime costs (including freight and spreading); casual labour costs; machinery maintenance and repair costs. All these costs were linked to the activities modelled in APSIM (such as the amount of fertiliser used). Non-cropping costs, such as freight and casual labour, are calculated using average costs for the location and size of the case study farm.

The gross margin is a per-hectare, paddock-scale analysis. The farm incorporates multiple paddocks and soil types (see Figure 1) on which crop yields differ. The whole-farm economic analysis needs to account for this. We therefore calculate the total on-farm gross margin (as the sum of the gross margins for all soil types $i$ and crops $j$ - equation 2) minus the operating costs. The operating costs account for all costs and benefits that are not directly related to growing a crop, such as overheads, machinery costs, the farmer's income and capital improvements. The resulting operating profit (equation 2) captures the capacity for the farm to generate profits from cropping under different GHG abatement scenarios.

$$
\text { Operating profit }=\sum\left[\left(\text { yield }_{i j} \times \text { price }_{j}\right)-\text { variable cost }_{j}\right]-\text { operating costs }
$$

In this analysis, we also account for the farm balance sheet and annual finance and tax costs following the process outlined by Malcolm (2011, Figure 2). The profit after interest and tax gives an indication of the extra costs faced by farmers, and how these might change if they adopt new practices. We refer to this profit as 'annual profit'. For the case study farm presented here, tax is paid at 25 percent of taxable income and the farmer's wage is $\$ 60,000$ for each full time owner-manager plus 10 percent of any profits before tax and interest. This is to account for a farm owner who takes a minimum wage in less successful years and extra income in higher earning years. The starting balance of the farm, and hence finance costs, were based on the average level of farm debt for the central wheatbelt in Western Australia for the period 2005-2014 which was \$AUD 1 million (ABARES 2015). When in debt, interest is compounded quarterly at 8 percent. When in credit, interest is compounded quarterly at 3 percent. Machinery costs are represented as an annual cost to maintain the current machinery portfolio, the machinery portfolio is worth \$AUD 1.96 million. Annual costs for machinery are based on the purchase price, trade-in prices, and average life-span of the machinery and equipment.

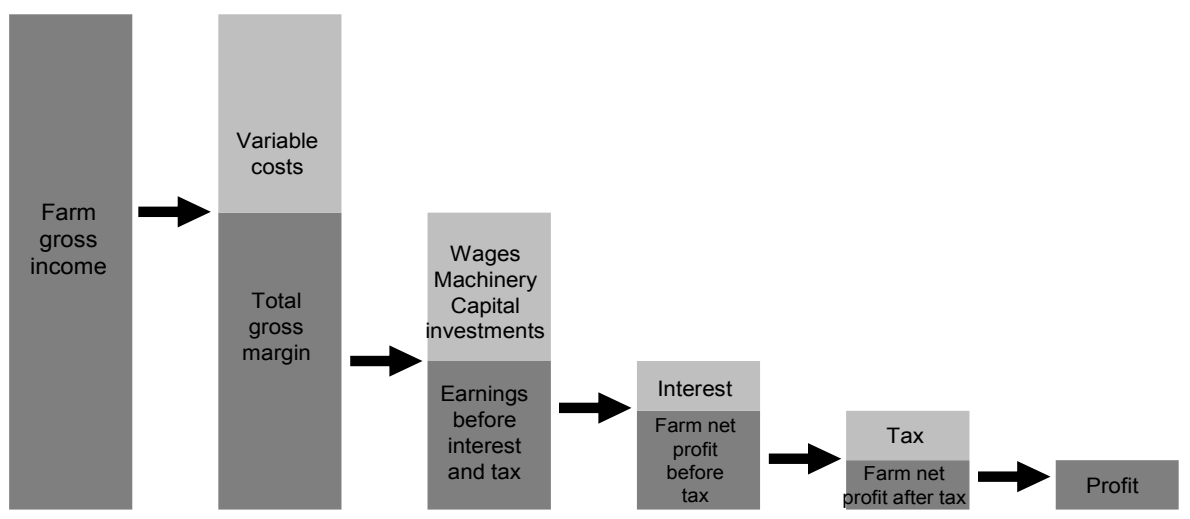

Figure 2. Whole-farm economic modelling process with stocks and flows of cash. Earnings before interest and tax is equivalent to operating profit (adapted from Malcolm (n.d) in GRDC 2013).

\footnotetext{
${ }^{1} 100-\mathrm{yr}$ GWP $=298$ for $\mathrm{N}_{2} \mathrm{O}$ and 3.67 for soil organic carbon (SOC).
} 


\section{RESULTS}

\subsection{Biophysical modelling: Crop yields and global warming potential}

The predicted crop yields for each scenario are compared to the baseline scenario to demonstrate net yield changes from the abatement practices. Predicted wheat yields were consistently lower ${ }^{2}$ than the baseline when less fertiliser was applied (Scenarios 4 and 6) and consistently higher with increased fertiliser rates or under improved pastures (Scenarios 5 and 9). These results indicate the importance of nitrogen fertiliser in maintaining and increasing yields. Canola and barley yields in the same rotation did not vary significantly across scenarios. Crop yields were more variable in the manure and summer cropping scenarios (Scenarios 7 and 8) than in other scenarios.

We considered the net global warming potential (GWP) of the various practices over a 25 and 100 year time scale. The predicted effects of management changes on GWP were similar across our seven soil types. We present results for two contrasting soils in Figure $3^{3}$. There was a consistent decrease in net GWP (i.e. reduction in GHG emissions) when stubble was retained (Scenarios 2, and 5 to 10). By comparison, there was no change in net GWP from burning stubble (Scenarios 3 and 4) compared to the baseline, even under variable nitrogen fertiliser rates.

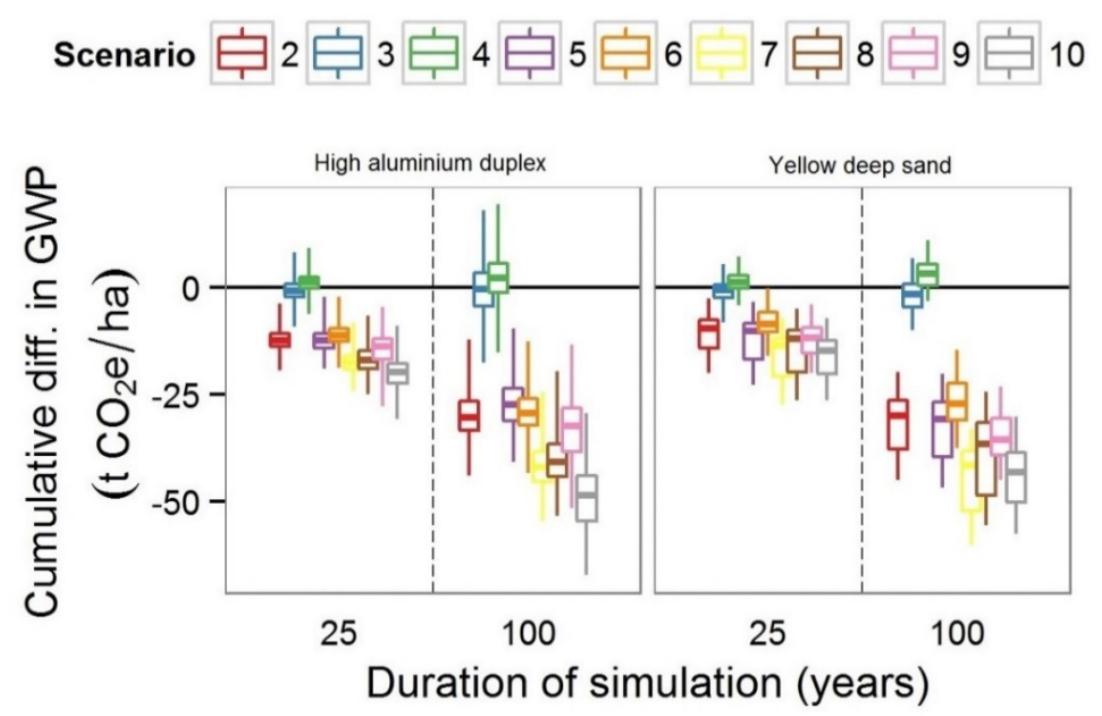

Figure 3. Difference in cumulative net global warming potential for abatement scenarios relative to baseline practices, shown for two soil types, and averaged across the three rotations. Box plots in each panel represent values at 25 and 100 years into the simulation period. Scenarios are described in Table 1.

\subsection{Economic model results}

The gross margins follow a similar pattern to yields. Scenarios 5 and 9 generate higher earnings compared to the baseline scenario (Table 2). Scenario 4, 8 and 10 result in significantly $(\mathrm{P}<0.05)$ lower gross margins compared to the baseline (Table 2). These results indicate that higher crop incomes are a major driver of the profitability of scenarios. The scenarios with higher yields and thus higher crop incomes are the most profitable (scenarios 5 and 9), despite other scenarios (scenarios 4 and 6) having lower variables costs. The gross margin and operating profits give an indication of net crop revenues, variable costs and operating costs, but do not capture the impact of finance and tax payments on the capacity to adopt new practices.

When interest and tax costs are taken into account (annual farm profits), there were no significant differences between the annual profits of the baseline scenario and the other scenarios (Table 2). This shows that any increase in profitability indicated by the gross margins are eroded by higher costs. For example, increased earnings could be eroded by increased tax payments (for these simulations, taxes were equal to $25 \%$ of taxable

\footnotetext{
${ }^{2}$ Results not shown

${ }^{3}$ The relative contribution of $\mathrm{N}_{2} \mathrm{O}$ vs change in soil organic carbon in the cumulative GWP is described by Meier et al. (2015) Greenhouse gas mitigation potential and profitability of practices on Australian grain farms. Proceedings of the 17th ASA Conference, $20-24$ September 2015, Hobart, Australia.
} 
income, so if gross margins are higher, taxable income will be higher). Our analysis also shows that in years with lower gross margins, farmers may save on tax and wages taken by the farm owner-managers.

Another important result from the whole-farm modelling compared to gross margin analysis is the difference in the number of years that net revenues are positive. Gross margins at the paddock scale are positive in all years and scenarios except for a small number of years in scenarios 6 and 7 (Table 2). However, when interest and tax costs are taken into account, the farm profits are negative in 30-40 percent of years. Therefore, not only is the profitability of carbon abatement practices lower in terms of annual whole-farm profits, but a farmer will also have to support additional financing costs in years with negative profits - something not revealed by a gross margin analysis.

Table 2. Average annual gross margins, operating profits and farm profits $(\$ /$ ha) and the number of years in a 100 year simulation when gross margins and farm profits were negative.

\begin{tabular}{cccccc}
\hline & $\begin{array}{c}\text { Average } \\
\text { annual gross } \\
\text { margin }(\$ / \text { ha })\end{array}$ & $\begin{array}{c}\text { Average annual } \\
\text { operating profit } \\
(\$ / \text { ha })\end{array}$ & $\begin{array}{c}\text { Average } \\
\text { annual farm } \\
\text { profit }(\$ / h a)\end{array}$ & $\begin{array}{c}\text { No. years with } \\
\text { negative gross } \\
\text { margin }\end{array}$ & $\begin{array}{c}\text { No. years with } \\
\text { negative } \\
\text { profits }\end{array}$ \\
\hline Scenario 1 & 223 & 164 & 40 & 0 & 35 \\
Scenario 2 & 237 & 178 & 45 & 0 & 30 \\
Scenario 3 & 233 & 174 & 42 & 0 & 38 \\
Scenario 4 & $199^{*}$ & $140^{*}$ & 35 & 0 & 34 \\
Scenario 5 & $251^{*}$ & $192^{*}$ & 47 & 0 & 30 \\
Scenario 6 & 205 & 146 & 38 & 1 & 33 \\
Scenario 7 & 224 & 164 & 42 & 10 & 32 \\
Scenario 8 & $190^{*}$ & $131^{*}$ & 34 & 0 & 34 \\
Scenario 9 & $241^{*}$ & $194^{*}$ & 48 & 0 & 29 \\
Scenario 10 & $192^{*}$ & $132^{*}$ & 32 & 0 & 40 \\
Note: ${ }^{*}=$ Gross margins and operating profits that are significantly different from the baseline (scenario 1) at $\mathrm{p}=0.05$
\end{tabular}

\section{DISCUSSION AND CONCLUSIONS}

Our study investigates the opportunities for farmers to adopt 'carbon farming' practices that are both profitable and deliver GHG abatement. The analysis was done for a 6,000 hectare, dryland, grain farm in the wheatbelt of Western Australia. Seven of the nine GHG abatement scenarios that we simulated were successful in reducing GHG emissions compared to baseline farm practices in the case study region. Some abatement scenarios - namely retaining stubble and increasing $\mathrm{N}$ fertiliser rates (Scenario 5) and replacing weedy pastures with improved legume pastures (Scenario 9) - can achieve GHG abatement, productivity improvements, and increase farm operating profits. However, after accounting for interest and tax, we did not find significant differences in profitability between the baseline practices and GHG abatement scenarios.

An important finding of this study is the insights gained from using different economic analyses: gross margins, whole-farm operating profit, or an analysis that incorporates interest and tax when determining the change in relative profitability between farming practices. While a gross margin approach is a necessary step in the whole-farm economic analysis, it is important to account for farm costs that are not directly related to cropping activities. The whole-farm operating profits allow us to capture the costs of running the farm, providing a better indication of profitability differences between scenarios. This analysis also allows us to compare farming systems that require different capital or infrastructure (e.g. dryland grain with an irrigated cotton system). Such whole-farm economic comparison is important to assess the effectiveness of nation-wide policy schemes (e.g. carbon prices). Finally, considering interest and tax impacts would reflect the manager's financial business, rather than cropping, skills. Nevertheless, such an analysis would give an important indication of the business' capacity to adopt new practices with upfront costs. Policy makers will need to consider these findings when they use different economic modelling results to support decision making.

\section{ACKNOWLEDGEMENTS}

This project is supported by funding from the Australian Government Department of Agriculture, and the Grain Research \& Development Corporation (GRDC). Case study farm information provided though collaboration with the Liebe Group (www.liebegroup.org.au) and supplementary field experiment data used to test APSIM provided by Dr Frances Hoyle is appreciated. 


\section{REFERENCES}

ABARES (2015), AGSURF: farm survey data. Available from: www.apps.daff.gov.au/AGSURF. Accessed $15 / 02 / 2015$.

Campbell, G.S. (1985), Soil Physics with Basic: Transport models for soil-plant systems. Elsevier, Amsterdam.

Dalal, R.C., Wang, W.J., Robertson, G.P., and Parton, W.J. (2003), Nitrous oxide emission from Australian agricultural lands and mitigation options: a review, Australian Journal of Soil Research 41 (2), 165-195.

DCCEE (2010), National Greenhouse Gas Inventory - Kyoto Protocol Accounting Framework. Canberra, ACT, Commonwealth of Australia.

FAO (2009), How to Feed the World in 2050. Outcomes of the High Level Expert Forum on How to Feed the World in 2050, 12-13 October 2009, Rome, Italy.

http://www.fao.org/fileadmin/templates/wsfs/docs/expert_paper/How to_Feed the_World_in_2050.pdf GRDC (2013), Farm financial tool: Profit and loss budget, Fact Sheet, November 2013, Kingston, ACT.

Holzworth, D.P, Huth, N.I., deVoil, P.G., et al. (2014), APSIM - Evolution towards a new generation of agricultural systems simulation, Environmental Modelling and Software 62, 327-350.

Huth, N. I., Thorburn, P. J., Radford, B. J., and Thornton, C. M. (2010), Impacts of fertilisers and legumes on $\mathrm{N}_{2} \mathrm{O}$ and $\mathrm{CO}_{2}$ emissions from soils in subtropical agricultural systems: A simulation study, Agriculture, Ecosystems and Environment, 136, 351-357.

IPCC (2013), Climate Change 2013: The Physical Science Basis. Contribution of Working Group I to the Fifth Assessment Report of the Intergovernmental Panel on Climate Change [Stocker, T.F., D. Qin, G.-K. Plattner, M. Tignor, S.K. Allen, J. Boschung, A. Nauels, Y. Xia, V. Bex and P.M. Midgley (eds.)]. Cambridge University Press, Cambridge, United Kingdom and New York, NY, USA, 1535 pp.

Jeffrey, S.J., Carter, J.O., Moodie, K.M., and Beswick, A.R. (2001), Using spatial interpolation to construct a comprehensive archive of Australian climate data, Environmental Modelling and Software 16, 309-330.

Kragt, M. E., and Robertson, M. J. (2014), Quantifying ecosystem services trade-offs from agricultural practices, Ecological Economics, 102, 147-157.

Luo, Z.K., Wang, E.L., and Sun, O.J. (2010), Soil carbon change and its responses to agricultural practices in Australian agro-ecosystems: a review and synthesis, Geoderma, 155 (3-4), 211-223.

Malcolm, B. (2011), Financing matters, Australian Farm Business Management, 8 (1), 11-18.

Pannell, D. J., Marshall, G. R., Barr, N., Curtis, A., Vanclay, F., and Wilkinson, R. (2006), Understanding and promoting the adoption of conservation practices by rural landholders, Australian Journal of Experimental Agriculture, 46, 1407-1424.

Parliament of the Commonwealth of Australia (2014), Carbon Farming Initiative Amendment Bill, Explanatory Memorandum. Canberra, ACT.

Probert, M.E., Dimes, J.P., Keating, B.A., Dalal, R.C., and Strong, W.M. (1998), APSIM's water and nitrogen modules and simulation of the dynamics of water and nitrogen in fallow systems. Agricultural Systems 56, 128.

Rochecouste, J. F., Dargusch, P., Cameron, D., and Smith, C. (2015), An analysis of the socio-economic factors influencing the adoption of conservation agriculture as a climate change mitigation activity in Australian dryland grain production, Agricultural Systems, 135, 20-30.

Thorburn P.J., Probert M.E., and Robertson F.A. (2001), Modelling decomposition of sugar cane surface residues with APSIM-Residue, Field Crops Research 70, 223-232.

Thorburn, P.J., Biggs, J.S., Collins, K., and Probert, M.E. (2010), Using the APSIM model to estimate nitrous oxide emissions from diverse Australian sugarcane production systems, Agriculture, Ecosystems and Environment 136, 343-350.

University of Melbourne (2001) Outline maps, Available from: www.lib.unimelb.edu.au/collections/maps/digital/outline-maps/ 